\title{
Countercurrent arterial contrast echocardiography in the assessment of left to right ductal shunting in preterm infants
}

\author{
N J ELZENGA AND R SPRITZER \\ Department of Paediatrics, Erasmus University and University Hospital and Sophia Children's Hospital, \\ Rotterdam, The Netherlands
}

SUMMARY A method of performing contrast echocardiography for the assessment of left to right ductal shunting in infants in a neonatal intensive care unit is described. Echo contrast was obtained by countercurrent injection of a small volume of blood through a radial artery canula. The technique was simple and reliable in 32 infants and no serious adverse reactions were observed.

Prolonged patency of the ductus arteriosus is common in preterm infants. The increase in the reported incidence during the past decade is principally related to improved neonatal intensive care and improved survival of small infants. There has been, in addition, a growing awareness of the problem coupled with more reliable methods of diagnosis. The typical clinical signs, such as a heart murmur, wide pulse pressure, and congestive heart failure, are known to be unreliable for the assessment of patent ductus arteriosus. ${ }^{1-4}$ The indirect methods of assessing a left to right shunt include measurement of the ratio of aortic root diameter to left atrial diameter using $\mathrm{M}$ mode echocardiography, ${ }^{5}$ diastolic pressure analysis, ${ }^{6}$ and Doppler ultrasonic evaluation of brachial artery flow. ${ }^{7}$

Although echocardiography and Doppler techniques have proved reliable in detecting even small left to right ductal shunts, ${ }^{28}$ they are not yet widely used. Left to right shunts may also be detected by direct measurement at cardiac catheterisation but this method is hazardous in very small infants and is not commonly used. Shunting through a patent ductus can, in addition, be visualised directly by aortography ${ }^{4}$ or by arterial contrast echocardiography. ${ }^{3}$ The purpose of this report is to describe a simple, safe, and reliable method of performing arterial contrast echocardiography in a neonatal intensive care unit to detect shunting from the aorta to the pulmonary artery.

\section{Patients and methods}

Indwelling radial artery canulas have been used routinely in our neonatal intensive care unit since 1975 for continuous blood pressure monitoring and blood gas sampling. They are inserted percutaneously using the technique described by Pearse. ${ }^{10}$ We have used either right or left radial artery canulas for countercurrent contrast echocardiography to assess left to right shunting through the ductus arteriosus. Thirty two critically ill, mostly preterm infants requiring intermittent positive pressure ventilation were studied. Their gestational ages ranged from 26 to 38 weeks (mean 30.5 weeks) and birthweights from 680 to $2800 \mathrm{~g}$ (mean $1480 \mathrm{~g}$ ). The mean postnatal age of the infants at the time of study was 12 days (range 4 hours to 33 days). Six of the infants were studied again after surgical ligation of their ductus. A blood sample of $0.5 \mathrm{ml} / \mathrm{kg}$ body weight was drawn from the radial artery canula into a 1 or $2 \mathrm{cc}$ syringe. Care was taken to remove all air bubbles from the syringe, stopcock, and connecting tube. An ATL mechanical sector scanner incorporating a $5 \mathrm{MHz}$ transducer was used to obtain cross sectional echocardiograms of the great arteries.

Tomographic planes were selected to visualise both the pulmonary artery or one of its main branches and part of the aortic arch or proximal descending aorta. In practice the two most useful planes were the subcostal long axis section showing the pulmonary artery and descending aorta, and the high left parasternal subclavicular view showing the aortic arch and right pulmonary artery simultaneously. When adequate pictures were thus obtained the blood sample from the radial artery was rapidly reinjected into the canula. This procedure was repeated at least two times in both echo 
planes. Heart rate was continuously monitored throughout the procedure; systemic blood pressure was measured through the radial artery canula before and after the procedure.

\section{Results}

Satisfactory images were obtained from the subcostal long axis view in all infants (Fig. 1). The high left parasternal view (Fig. 2) was unsuccessful in four infants with severe pulmonary disease and hyperinflated lungs and in two children with chest drains for left sided pneumothoraces. The appearance of contrast echoes in the aortic arch or the descending aorta after the peripheral arterial injection of blood was used as a marker for the adequacy of the injection. A volume of $0.5 \mathrm{ml} / \mathrm{kg}$ body weight was found to be sufficient to give clear contrast in the aorta in all infants, although on some occasions single injections failed to result in aortic contrast.

A left to right shunt through the ductus was diagnosed when echocontrast was observed in the pulmonary artery after the injection of blood into the radial artery canula (positive contrast study). Only a crude assessment could be made of the magnitude of the shunt. If the contrast in the pulmonary artery was less dense than the contrast in the aorta, the shunt was considered to be small. If pulmonary artery contrast seemed to be as dense as or denser than aortic contrast, the shunt was considered large. The absence of a left to right ductal shunt was diagnosed when no echocontrast was observed in the pulmonary artery (negative contrast study).

A left to right ductal shunt was established in 24 of the 32 infants. Eighteen of the 24 infants with a left to right ductal shunt underwent surgical ligation of their ductus. Seventeen of these 18 infants had a large shunt at the echocontrast study. At surgery wide patency was observed in 16 patients and moderate patency in two. One infant with a small left to right ductal shunt and severe pulmonary disease died. At necropsy a narrow patent ductus arteriosus was present.

No left to right ductal shunt was found at the time of the contrast study in 8 infants. One of these infants had a persistent fetal circulation syndrome and a proved right to left ductal shunt. One infant was found to have a narrow patent ductus at cardiac catheterisation 6 months later. The remaining 6 patients did not develop clinical signs of a patent ductus with left to right shunt and were weaned from
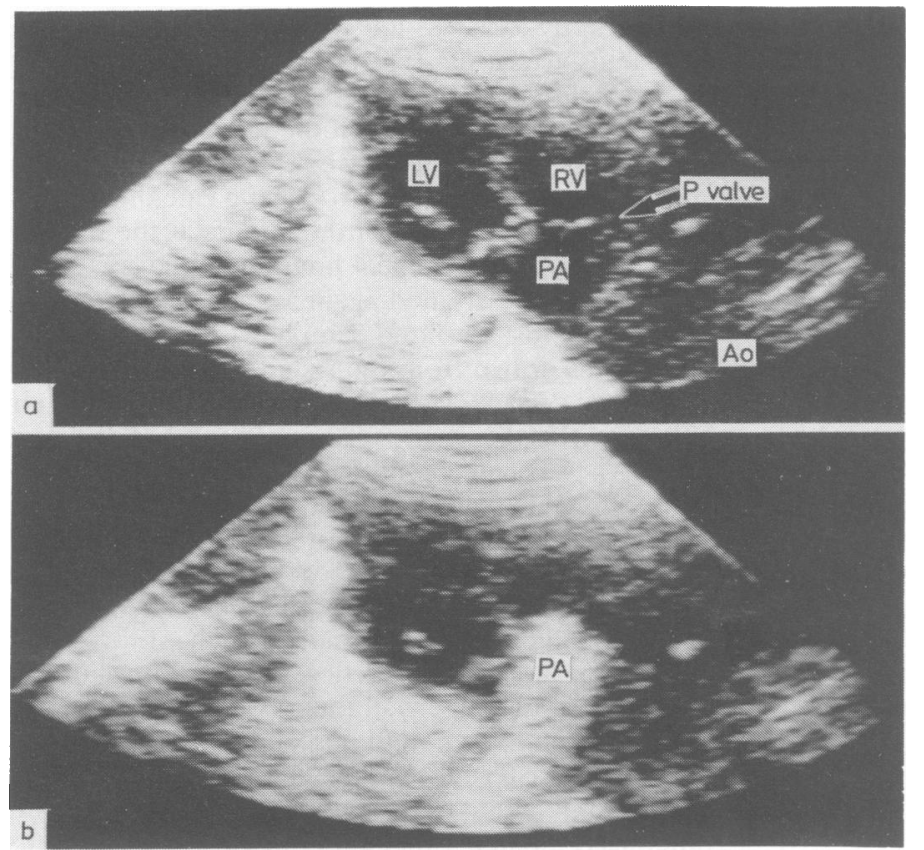

Fig. 1 Subcostal long axis view before (a) and shortly after (b) contrast injection. $L V=$ left ventricle, $R V=$ right ventricle, $P A=$ main pulmonary artery, $A o=$ aorta, $P$ valve=pulmonary valve. Very dense contrast in the PA indicating a large left to right ductal shunt is seen in $(b)$. 


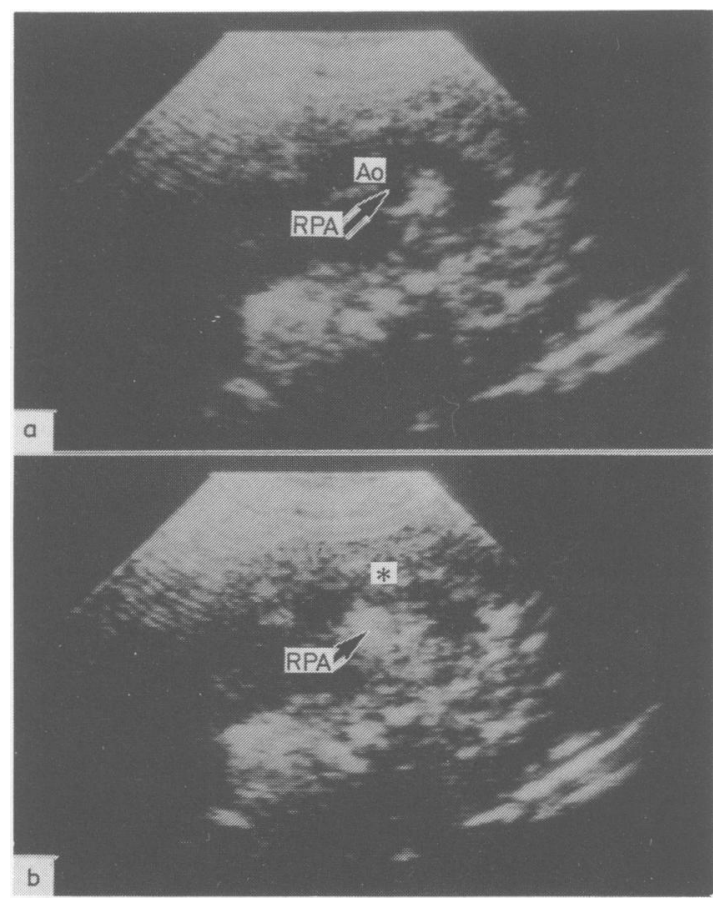

Fig. 2 High left parasternal view before (a) and after (b) contrast injection. $R P A=$ right pulmonary artery. In (b) dense contrast is seen in the RPA and some contrast (") in the aorta.

the ventilator successfully. Additionally, 6 negative contrast studies were obtained in the 6 infants who were studied again after surgical ligation of their ductus.

Mild transient bradycardia occurred in 10 infants shortly after a single injection. One infant, however, developed a profound bradycardia of $70 / \mathrm{min}$ that lasted for 30 seconds. During repeated injections the bradycardia recurred, although less severely than after the first injection. Radial arterial blood pressure tended to increase slightly after the study (5 to $10 \mathrm{mmHg}$ systolic increase) but returned to normal within 10 to 15 minutes. No neurological sequelae related to countercurrent echoconstrast study were seen.

\section{Discussion}

Countercurrent arterial radiopaque contrast injection was first reported in 1940. ${ }^{11}$ Aortography was performed thus in the 1940s and 50s for assessment of patent ductus arteriosus and coarctation. ${ }^{12} 13$ When retrograde left heart catheterisation became possible in the 1950 s the countercurrent technique was apparently abandoned. Recently, however, Ueda et al ${ }^{9}$ reinstituted the technique for assessment of aortic arch anomalies and patent ductus arteriosus in small infants in whom retrograde arterial catheterisation may be hazardous. Our own experience has been equally favourable and we have used countercurrent radiopaque aortography in selected infants and children with complex cardiac defects. Arterial contrast echocardiography has been reported to be a reliable method for assessment of even small left to right ductal shunts in preterm infants. ${ }^{12}$ These authors, however, ${ }^{12}$ have used umbilical artery catheters with their tips positioned proximal to the origin of the ductus.

We developed the countercurrent echo contrast technique because it seemed a simple, safe, and reliable method and because indwelling radial artery canulas are routinely used in our neonatal intensive care unit. We have never encountered serious complication with these canulas ${ }^{10}$ and agree with others $^{1415}$ in advocating their wider use. Both left and right radial arteries were used for the injection of blood. Injection in the left radial artery resulted in very clear contrast in the distal part of the aortic arch and descending aorta. Injection in the right radial artery, however, gave less bright contrast in the distal part of the aortic arch since part of the contrast entered the brachiocephalic vessels. When a left artery is used a sample smaller than $0.5 \mathrm{ml} / \mathrm{kg}$ body weight is probably sufficient.

Countercurrent arterial contrast echocardiography seemed to be a reliable method for the assessment of a left to right ductal shunt. The patency of the ductus was proved in 19 of the 24 infants with positive contrast studies-18 at surgery and one at necropsy. The very high percentage of patients undergoing surgery was due to patient selection. Only infants needing prolonged ventilatory support and monitored with indwelling radial artery canulas were studied.

The 6 infants who were studied again after surgery were all negative, indicating that there were no false positives. A negative contrast study, however, does not exclude a patent ductus. A right to left ductal shunt may be present, as in one of our infants with persistent fetal circulation. Furthermore, a very small left to right shunt may not be detected and we probably missed this in at least one infant. This child had a small patent ductus at cardiac catheterisation performed 6 months later. Variability in the degree of ductal constriction may also be a cause of false negatives.

Major complications of the countercurrent injection were not observed. The transient bradycardia and raised blood pressure did not influence the clinical well being of our patients. To our knowledge 
this type of adverse reaction to countercurrent injection has not been reported previously and may be related to low birthweight of the infants.

Direct visualisation of the ductus with crosssectional echocardiography has not been successful in small intubated infants in our experience but the technique described by Smallhorn ${ }^{16}$ seems very promising. We are convinced, however, that it is the left to right shunt that causes the respiratory problems in preterm infants with patent ductus arteriosus. The direction and magnitude of the shunt are not only determined by the diameter of the ductus but also by the ratio of the pulmonary to systemic vascular resistances, the latter varying considerable in the individual patient. We have shown that countercurrent arterial contrast echocardiography can be very useful in selecting those infants who are likely to benefit from ligation of the ductus.

The authors wish to thank Dr M Rigby for his critical review of the manuscript.

\section{References}

1 Allen HD, Sahn DJ, Goldberg SJ. New serial contrast technique for assessment of left to right shunting patent ductus arteriosus in the neonate. Am J Cardiol 1978;41:288-94.

2 Daniels $O$. The open ductus Botalli and the respiratory distress syndrome. Nijmegen University, 1982. (Thesis).

3 Valdes-Cruz LM, Dudell GG. Specificity and accuracy of echocardiographic and clinical criteria for diagnosis of patent ductus arteriosus in fluid restricted infants. $J$ Pediatr 1981;98:298-305.

4 Thibeault DW, Emmanouilides GG, Nelson RJ, Lachman RS, Rosengart RJ, Oh W. Patent ductus arteriosus complicating the respiratory distress syndrome in preterm infants. $J$ Pediatr 1975;86:120-6.

5 Silverman NH, Lewis AB, Heyman MA. Echocardiographic assessment of ductus arteriosus shunt in premature infants Circulation 1975;50:82!-5.

${ }^{6}$ Milstein JM. Ricmenschneider TA, Goetzman BW, George L, Weinberg RP. Assessment of patent ductus arteriosus shunting using diastolic pressure analysis. J Pediatr 1979;94:122-6.

7 Feldtman RV. Andrassy RJ, Alexandre JA, Stanford W. Doppler ultrasonic flow detection as an adjunct in the diagnosis of patent ductus arteriosus in premature infants. $J$ Thorac Cardiovasc Surg 1976:72:288-90.

* Stevenson JG, Dooley T, Kawabori I. Patent ductus arteriosus in a neonatal intensive care unit: the utility of pulsed doppler echocardiography. Circulation 1978;58(Suppl II):110-2.

${ }^{y}$ Ueda K, Saito A, Nakano H. Aortography by countercurrent injection via the radial artery in infants with congenital heart disease. Pediatr Cardiol 1982;2:231-6.

10 Pearse RG. Percutaneous catheterization of the radial artery in newborn babies using transillumination. Arch Dis Child 1978:53:549-54.

"Castellanos A, Pereiras R. Countercurrent aortography. Revista cubana de cardiologia 1940;2:187-93.

12 Perez de los Reyes R, Castellanos A, Pereiras R. Angiocardiography and its valuc. Am Heart J 1942;25:298-306.

13 Keith JD, Forryth C. Aortography in infants. Circulation 1950;2:9(07-14.

it Todres ID, Rogers MC, Shannon DC, Moylan FMB, Ryan JF. Percutaneous catheterization of the radial artery in the critically ill neonatc. J Pediatr 1975;87:273-5.

15 Adams JM, Rudolph AJ. The use of indwelling radial artery canulas in nconates. Pediatrics 1975:55:261-5.

16 Smallhorn JF, Huhta JC, Anderson RH, Macartncy FJ. Suprasternal cross sectional echocardiography in assessment of patent ductus arteriosus. $\mathrm{Br}$ Heart $J$ 1982;48:321-30.

Correspondence to Dr N J Elzenga, Sophia Children's Hospital. Gordelweg 160, 3038 GE Rotterdam, PO Box 70029, 3000) LL Rotterdam. The Netherlands.

Received 13 February 1984. 